\title{
Initiation and persistence with warfarin therapy in atrial fibrillation according to ethnicity
}

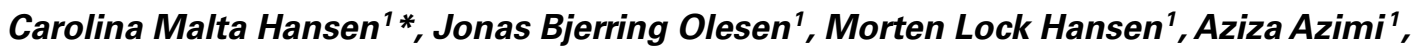 Christian Torp-Pedersen ${ }^{1}$ and Helena Dominguez ${ }^{2}$}

1 Department of Cardiology, Copenhagen University Hospital Gentofte, Hellerup, Denmark

2 Department of Cardiology, Copenhagen University Hospital Herlev, Denmark

\section{Edited by:}

Michael P. Jones, Macquarie

University, Australia

Reviewed by:

Dominique J. Dubois, Université Libre de Bruxelles, Belgium

Michael Hans Thiede, Health

Economics and Policy, Germany

*Correspondence:

Carolina Malta Hansen, Department of Cardiology, Copenhagen University Hospital Gentofte, Niels Andersens vej 65, Post 635, Hellerup, Denmark. e-mail:cmh@heart.dk
The aim of this study was to investigate initiation of and persistence with warfarin treatment in patients with atrial fibrillation (AF) according to ethnicity. Patients hospitalized with first-time AF from 1997 to 2009, prescription claims of warfarin and country of birth were identified by individual-level linkage of nationwide administrative agencies. Cox proportional hazards models were used to estimate the relationship between covariates affecting initiation and non-persistence with warfarin treatment. A total of 151,537 patients were included in the study and 5,061(3.3\%) were of non-Danish origin. CHADS2 score distribution varied substantially according to ethnicity, the proportion of patients with CHADS2 score $\geq 1$ being 79.2, 78.1, 65.9, and $46.0 \%$ for patients of Danish, Western, Eastern, and African origin, respectively. 79,239(52.4\%) of all patients initiated treatment with warfarin at some point in time. Multivariable Cox proportional hazard analyses indicated patients of Eastern and African origin were less likely to initiate warfarin therapy (HR 0.75; 95\% $\mathrm{Cl} 0.69-0.82$ and HR $0.58 ; 95 \% \mathrm{Cl} 0.44-0.76$, respectively). Patients of Eastern origin were more likely to interrupt treatment (HR 1.23; $95 \% \mathrm{Cl} 1.02-1.47$; for all patients; HR 1.62; 95\% Cl 1.22-2.16; for patients with CHADS2 score $>1$ ). African origin was associated with a trend to interrupt treatment (HR 1.44; 95\% Cl 0.46-4.47; for patients with CHADS2 score $>1$ ). Initiation of and persistence with warfarin in AF patients is lower among patients of Eastern and African origin compared to patients of Danish and Western origin, despite equal access to health care and medication. Future studies should address, beyond ethnicity, all possible driving factors of (non)initiation and persistence with treatment in general. This will be particularly interesting in light of the new generation of anticoagulants, which might render different adherence to treatment.

Keywords: atrial fibrillation, ethnicity, VKA treatment, warfarin, adherence

\section{INTRODUCTION}

Patients with atrial fibrillation $(\mathrm{AF})$ are at increased risk of thromboembolism and stroke, and the benefit from vitamin $\mathrm{K}$ antagonists (VKA) for stroke prevention in AF patients has been extensively documented (Hughes and Lip, 2008; Camm et al., 2010; Olesen et al., 2011). Consequently, VKA therapy is recommended for patients with $\mathrm{AF}$ who have additional risk factors for stroke. However, substantial underuse of VKA has been reported in spite of existing guidelines (Ogilvie et al., 2010).

The clinical and economic consequences of under using VKA therapy are profound and understanding factors that determine VKA use may improve the quality of care for patients with AF. This is of particular interest in light of the new generation of anticoagulants that may render different adherence to treatment.

Ethnicity has been associated with differences in cardiovascular health parameters and clinical outcomes (Balarajan, 1991; Benner et al., 2002; Kaplan et al., 2004; Hertz et al., 2007; Harding et al., 2008; Cooper et al., 2009; McWilliams et al., 2009; Dominguez et al., 2010; Hempler et al., 2010), even when differences in socioeconomic profiles are equalized (Mayberry et al., 2000; Trivedi et al., 2006; Hertz et al., 2007; Hozawa et al., 2007).
Limited data has been published concerning the use of VKA for patients with AF according to ethnicity (Lip et al., 1998; Schauer et al., 2007). Thus, more comprehensive analyses are needed to identify possible underuse of VKA in ethnic groups in order to define targets for improvement in anticoagulation treatment.

The aim of this study was to investigate the initiation of and persistence to warfarin treatment according to ethnicity in patients with first-time AF hospitalization between 1997 and 2009.

\section{MATERIALS AND METHODS}

All permanent residents in Denmark have a unique civil registration number which enables linkage between national registries on an individual basis. The cohort of patients selected for this study was identified using the Danish National Patient Registry, which has kept records of all hospitalizations in Denmark since 1978. All patients hospitalized with first-time AF [International Classification of Diseases, 10th revision (ICD-10), code I48, International Classification of Diseases, 8th revision (ICD-8), code 42793, 42794] as a primary or secondary diagnosis between 1997 and 2009 were identified. Patients aged $\geq 30$ years were included in the analyses. Since drug treatment may be altered during hospital 
admission, follow-up initiated 7 days after discharge (index date). Patients who died within 7 days after discharge were excluded from the study.

For the present study, SAS statistical software version 9.2 was used for data collection.

\section{ETHNICITY}

The main concern was to address cultural and not racial ethnicity. To take the effect of cultural legacy into consideration, we constructed a more refined ethnicity proxy, "country of origin," based on the parents' country of birth for a given individual. Two simple ethnicity parameters were used, country of birth and citizenship.

To be considered of Danish origin, the subject needed at least one parent who was born in Denmark and who holds Danish citizenship, regardless of the subject's own citizenship or country of birth. Persons whose parents did not fulfill these criteria were classified as being of "non-Danish origin." The patient's country of origin was then defined by the mother's country of birth, if data were available and if not, by the individual's own country of birth. Countries were grouped into four categories to form four large ethnic origins: (1) "Danish origin" as explained above; (2) "Western origin" which included Baltic countries, the Americas, Oceania, and most European countries other than Denmark; (3) "Eastern countries" which included all countries from the Asian continent and countries from Eastern Europe considered to be more culturally related to Asia including Turkey, Russia, Slovakia, Czech republic, Ukraine, and Belarus; and (4) "African origin" which included all countries from the African continent, as described in detail previously (Dominguez et al., 2010).

\section{MEDICAL TREATMENT}

Information on the use of pharmacotherapy was obtained from the Registry of Medicinal Product Statistics (national prescription registry) that has existed since 1995 . The registry keeps information about all prescriptions dispensed from Danish pharmacies including prescribed drugs, date of dispensing, strength, quantity dispensed, and the affiliation of the doctor issuing the prescription. Each prescribed drug is coded according to an international classification of pharmaceuticals, the anatomical therapeutic chemical (ATC) classification. The registry has been found to be accurate and has been described in more detail previously (Gaist et al., 1997). Warfarin was identified using the ATC code B01AA03. All subjects who claimed a prescription of warfarin during the period 1997-2009 were identified. Initiation of treatment was registered in relation to the index date. We defined non-persistence as a break in treatment of 90 days or more based on previous findings that patients who interrupted their treatment for less than 90 days were prone to re-initiate treatment (Gislason et al., 2006).

\section{CO-MORBIDITY - THROMBOEMBOLIC RISK ASSESSMENT}

Patients who claimed a prescription for a glucose lowering drug (A10) were defined as having diabetes mellitus. We identified patients with hypertension from combination treatment with at least two of the following classes of antihypertensive drugs: $\alpha$ adrenergic blockers (C02A, C02B, C02C), non-loopdiuretics (C02DA, C02L, C03A, C03B, C03D, C03E, C03X, C07C, C07D, C08G, C09BA, C09DA, C09XA52), vasodilators (C02DB, C02DD, C02DG, C04, C05), $\beta$-blockers (C07), calcium channel blockers (C07F, C08, C09BB, C09DB), and renin-angiotensin system inhibitors (C09). This definition of hypertension has been well validated with a high specificity and sensitivity, as previously described in detail (Ekholm et al., 2009; Olesen et al., 2011).

Previous thromboembolism and vascular disease were identified through the national patient registry. Thromboembolism was defined as peripheral artery embolism, stroke and transient ischemic attack (433-438, 444, G458, G459, I63, I64, I74), and vascular disease was defined as ischemic heart disease, peripheral artery disease, and aortic plaque (410-414, 440, I21, I22, I700, I702-709; Madsen et al., 2003; Krarup et al., 2007; Joensen et al., 2009; Lip et al., 2010; Severinsen et al., 2010).

Congestive heart failure was defined as the combination of previous diagnoses of heart failure, registered in the national patient registry under the following codes $425,4270,4271$, I110, I42, I50, J819, and treatment with loop-diuretics (C03C; Kumler et al., 2008).

The $\mathrm{CHADS}_{2}$ score was calculated by adding one point each for heart failure, hypertension, age $\geq 75$, diabetes, and two points for previous thromboembolism. Thus, the score ranged from 0 to 6 (Gage et al., 2001).

\section{VITAL STATUS}

Information about each patient's vital status was obtained through the Civil Registration System which records all cases of death within 2 weeks.

\section{STATISTICAL ANALYSIS}

The relationship between time from index date (discharge date plus 7 days) to initiation of therapy and time to first break in therapy of 90 days or more were evaluated with Kaplan-Meier estimators (censored for death). Cox proportional hazards models were used to estimate the relationship between covariates affecting initiation and non-persistence with warfarin treatment. Time to first break in therapy of 90 days or more was tested in two analyses. We performed the first analysis without inclusion of $\mathrm{CHADS}_{2}$ score. Since patients with a low $\mathrm{CHADS}_{2}$ score (0-1) do not necessarily require long-term VKA therapy, for example in case of cardioversion, the analysis was repeated including only patients with $\mathrm{CHADS}_{2}$ score $>1$, in attempt to exclude from the analysis patients with intentional interruption of treatment. All models were adjusted for gender, age, ethnicity, and $\mathrm{CHADS}_{2}$ score.

We used SAS statistical software version 9.2 and Stata statistical software version 11.0 for the analyses.

\section{ETHICS}

This study was approved by the Danish Data Protection Agency (No. 2008-41-2685). Retrospective register-based studies do not require ethical approval in Denmark. Data collection, handling, and analyses were only accessible through Denmark Statistics. The civil registration number, used for the individual-level linkage of the different registries, was encrypted to the researches.

\section{RESULTS}

A total of 163,234 patients were hospitalized with first-time AF in Denmark between 1997 and 2009, 151,553 of which were aged $\geq 30$ years and survived 7 days after discharge. Due to uncertain ethnic origin, 16 patients were excluded. Hence, 151,537(92.7\%) 
patients were included in the analyses. Baseline characteristics of the population stratified by the ethnicity proxy "country of origin" are shown in Table 1.

The AF population comprised of 3.3\% patients of non-Danish origin, of which $2.5,0.8$, and $0.1 \%$ were of Western, Eastern, and African origin, respectively. The corresponding distribution of persons of non-Danish origin $5.9 \%$ of total population of Denmark) was 3.0\% Western, 2.5\% Eastern, and 0.4\% of African origin, as of December 31st, 2009. The small amount of patients of African origin ( $n=126)$ leads to power reduction, generally resulting in wider confidence intervals and higher $p$-values associated with African origin, meaning the results regarding this subgroup should be interpreted with caution.

There were considerable differences in thromboembolic risk factors of the cohort according to ethnicity (Table 1). The group of Western origin had similar characteristics to the group of Danish origin. Patients of Eastern and African origin were on average more than 10 years younger while only $21.3 \%$ of patients of Eastern origin and $8.7 \%$ of patients of African origin were 75 years-old or older. The younger age of AF patients of Eastern and African origin reflected well the age of the overall population of Eastern and African origin in Denmark, since the average age was 49 and 48 years for persons of Eastern and African origin, respectively, in contrast to 59 years for persons of Western and Danish origin. Patients of African origin had considerably less co-morbidity except from diabetes. The group of Eastern origin had the same prevalence of hypertension, lower prevalence of heart failure, and a higher prevalence of diabetes and previous ischemic heart disease compared to patients of Western and Danish origin. The overall difference in co-morbidity status and age between the ethnic groups resulted in a heterogeneous distribution of $\mathrm{CHADS}_{2}$ score, which is illustrated in Figure 1. Among patients of Danish origin, $79.2 \%$ had a CHADS 2 score of one or more in contrast to 65.9 and $46.0 \%$ of the Eastern and African populations, respectively. The results did not differ when using country of birth as the ethnicity proxy.

A total of 79,239(52.4\%) of all patients initiated treatment with warfarin at some point in time. The results were only slightly different when stratified by ethnicity. Of those who initiated treatment, $26,769(33.8 \%)$ initiated before admission, $31,973(40.3 \%)$ did so within the first 7 days after discharge, and 20,497(25.9\%) more than 7 days after discharge. Patients of Eastern origin were less likely to initiate treatment than patients of Western and Danish origin (HR 0.75; 95\% CI 0.69-0.82, $p<0.0001$ ) as were patients of African origin (HR 0.58; 95\% CI $0.44-0.76, p<0.0001$; Table 2; Figure 2).

Patients of Eastern origin were more prone to interrupt treatment compared to patients of Danish origin, since they had a higher hazard ratio to break in treatment of 90 days or more (Table 3). These results were found both in the analyses including all patients (HR 1.23; 95\% CI 1.02-1.47, $p=0.03$ ) and in the analyses that only included patients with $\mathrm{CHADS}_{2}$ score $>1$ (HR 1.62 ; 95\% CI 1.22-2.16, $p=0.001$ ). African origin was associated with a trend to interrupt treatment (HR 1.44; 95\% CI 0.46-4.47, $p=0.53)$ in the analysis including patients who have $\mathrm{CHADS}_{2}$ score $>1$, but the results were not statistically significant. Table 3 shows the results of a multivariable Cox proportional hazard analysis of time to first break of at least 90 days in Warfarin treatment, as proxy for non-persistence, for the different ethnic groups. Figure 3 shows long-term persistence to warfarin therapy stratified by ethnic origin.

\section{DISCUSSION}

This study indicates that patients of Asian and African origin with $\mathrm{AF}$ are at increased risk of not initiating and of discontinuing adequate warfarin treatment.

Few studies have been published on initiation of and persistence to treatment of cardiovascular disease according to ethnicity.

Table 1 | Baseline characteristics.

\begin{tabular}{|c|c|c|c|c|c|}
\hline \multirow[t]{2}{*}{ Characteristics } & \multirow[t]{2}{*}{ All origins } & \multirow[t]{2}{*}{ Danish origin } & \multicolumn{3}{|c|}{ Non-Danish origin } \\
\hline & & & Western origin & Eastern origin & African origin \\
\hline Total patients & $151,537(100 \%)$ & $146,492(96.7 \%)$ & $3,786(2.5 \%)$ & $1,133(0.8 \%)$ & $126(0.1 \%)$ \\
\hline Females & $71,320(47.1 \%)$ & $68,633(46.9 \%)$ & $2,125(56.1 \%)$ & $527(46.5 \%)$ & $35(27.8 \%)$ \\
\hline Mean age at presentation $\pm S D^{*}$, years & $73.6( \pm 12.4)$ & $73.7( \pm 12.3)$ & $73.1( \pm 12.6)$ & $63.8( \pm 13.5)$ & $56.9( \pm 13.4)$ \\
\hline Age $\geq 75$ & $77,765(51.3 \%)$ & $75,647(51.6 \%)$ & $1,866(49.3 \%)$ & $241(21.3 \%)$ & $11(8.7 \%)$ \\
\hline Heart failure & $33,772(22.3 \%)$ & $32,738(22.4 \%)$ & $796(21.0 \%)$ & $223(19.7 \%)$ & $15(11.9 \%)$ \\
\hline Hypertension & $69,315(45.7 \%)$ & $67,078(45.8 \%)$ & $1,692(44.7 \%)$ & $500(44.1 \%)$ & $45(35.1 \%)$ \\
\hline Diabetes & $13,829(9.1 \%)$ & $13,204(9.0 \%)$ & $376(9.9 \%)$ & $231(20.4 \%)$ & $18(14.3 \%)$ \\
\hline Previous stroke/TCl & $23,505(15.5 \%)$ & $22,806(15.6 \%)$ & $566(15.0 \%)$ & $122(10.8 \%)$ & $11(8.7 \%)$ \\
\hline Previous IHD & $33,985(22.4 \%)$ & $32,763(22.4 \%)$ & $880(23.2 \%)$ & $326(28.8 \%)$ & $16(12.7 \%)$ \\
\hline $\mathrm{CHADS}_{2}$ score $\geq 1$ & $119,834(79.1 \%)$ & $116,074(79.2 \%)$ & $2,955(78,1 \%)$ & 747 (65.9\%) & $58(46.0 \%)$ \\
\hline Warfarin treatment & $79,239(52.3 \%)$ & 76,711 (52.4\%) & $1,915(50.6 \%)$ & $556(49.1 \%)$ & $57(45.2 \%)$ \\
\hline
\end{tabular}

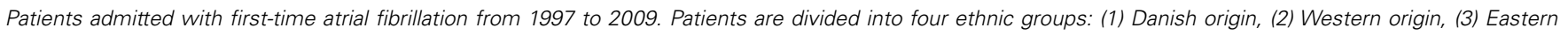
origin, and (4) African origin.

* SD, standard deviation; $\mathrm{CHADS}_{2}$ score of 1 or more includes those patients with at least one of the following.

Baseline characteristics; congestive heart failure, hypertension, 75 or more years of age, or stroke. 


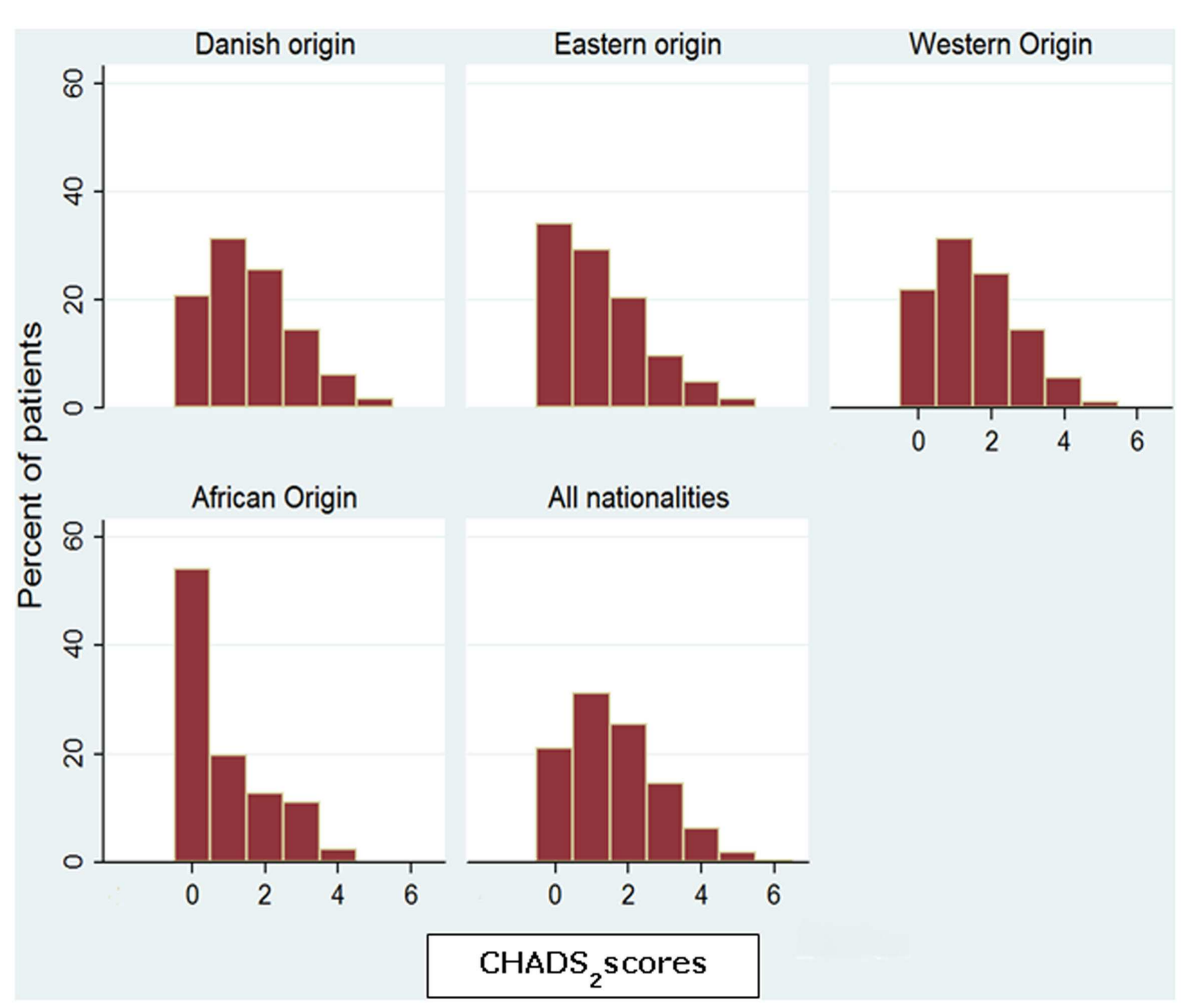

FIGURE 1 | $\mathrm{CHADS}_{2}$ scores distribution for all patients and divided into four ethnic groups: Danish origin, Eastern origin, Western origin, African origin.

Table 2 | Multivariate Cox logistic regression analysis: hazard ratio for initiation of warfarin treatment for patients discharged with first-time atrial fibrillation in the period 1997-2009 stratified by ethnic origin.

\begin{tabular}{lllll}
\hline $\begin{array}{l}\text { Patient } \\
\text { origin }\end{array}$ & $\begin{array}{l}\boldsymbol{N}=\text { number of } \\
\text { patients }\end{array}$ & $\begin{array}{l}\text { Hazard } \\
\text { ratio }\end{array}$ & $\begin{array}{l}\mathbf{9 5 \%} \text { Confidence } \\
\text { interval }\end{array}$ & $\boldsymbol{p}$-Value \\
\hline Danish & 146,492 & 1.00 & & \\
Eastern & 1,133 & 0.75 & $0.69-0.82$ & $<0.0001$ \\
Western & 3,786 & 0.95 & $0.91-1.00$ & 0.04 \\
African & 126 & 0.58 & $0.44-0.76$ & $<0.0001$ \\
\hline
\end{tabular}

All models were adjusted for gender, age, ethnicity, and $\mathrm{CHADS}_{2}$ score.

The existing data suggests ethnic minorities are likely to be undertreated (Lip et al., 1998; Schauer et al., 2007; Dominguez et al., 2010; Hempler et al., 2010). To our knowledge, none of the previous studies have investigated AF patients' compliance to warfarin therapy according to ethnicity. One previous study has examined adherence to warfarin therapy in American patients with AF according to race (African American/Whites), and found the minority to be undertreated (Schauer et al., 2007). There are no such studies in Europe. Our findings that Eastern and African origin are associated with inadequate warfarin therapy in a population of patients with AF complement earlier studies that found Eastern and African origin associated with inadequate treatment, in patients with previous acute myocardial infarction and diabetes (Lip et al., 1998; Dominguez et al., 2010; Hempler et al., 2010; Jenum et al., 2012).
Initiation of and persistence to treatment may be influenced by any number of factors such as socio-economic status (SES) and doctor-patient relationship (Schouten and Meeuwesen, 2006; Bates et al., 2009). Previous studies that examined therapy compliance according to ethnicity in Denmark have not found household income to influence compliance (Dominguez et al., 2010; Hempler et al., 2010). This could be due to high social equality, equal access to health care and educational systems, along with reimbursement for medical expenses for all residents in Denmark. However, ethnic background has been associated with differences in treatment and outcome, even when SES was found significant and adjusted for (Mayberry et al., 2000; Trivedi et al., 2006; Hertz et al., 2007; Hozawa et al., 2007; Kagawa-Singer et al., 2010).

Divergent cultural/ethnic backgrounds between doctor and patient have been associated with worse doctor-patient relationship, even after adjusting for socio-economic variables (Schouten and Meeuwesen, 2006; Kagawa-Singer et al., 2010). Several factors have been proposed to explain the relationship between doctors and patients from different ethnic/cultural backgrounds. Among these factors, language has been the most commonly addressed in the literature, since it poses challenges to doctor-patient communication and thereby induces non-compliance. However, doctorpatient relationship comprises aspects other than language skills, possibly even more so, when it comes to individuals with different cultural backgrounds (Schouten and Meeuwesen, 2006). Aspects like perceptual bias, i.e., how an individual with a certain origin is perceived by the doctor and vice-versa, and the patient's preference for different types of doctor-patient relationships are 


\section{Proportion of patients in warfarin therapy stratified by ethnicity}

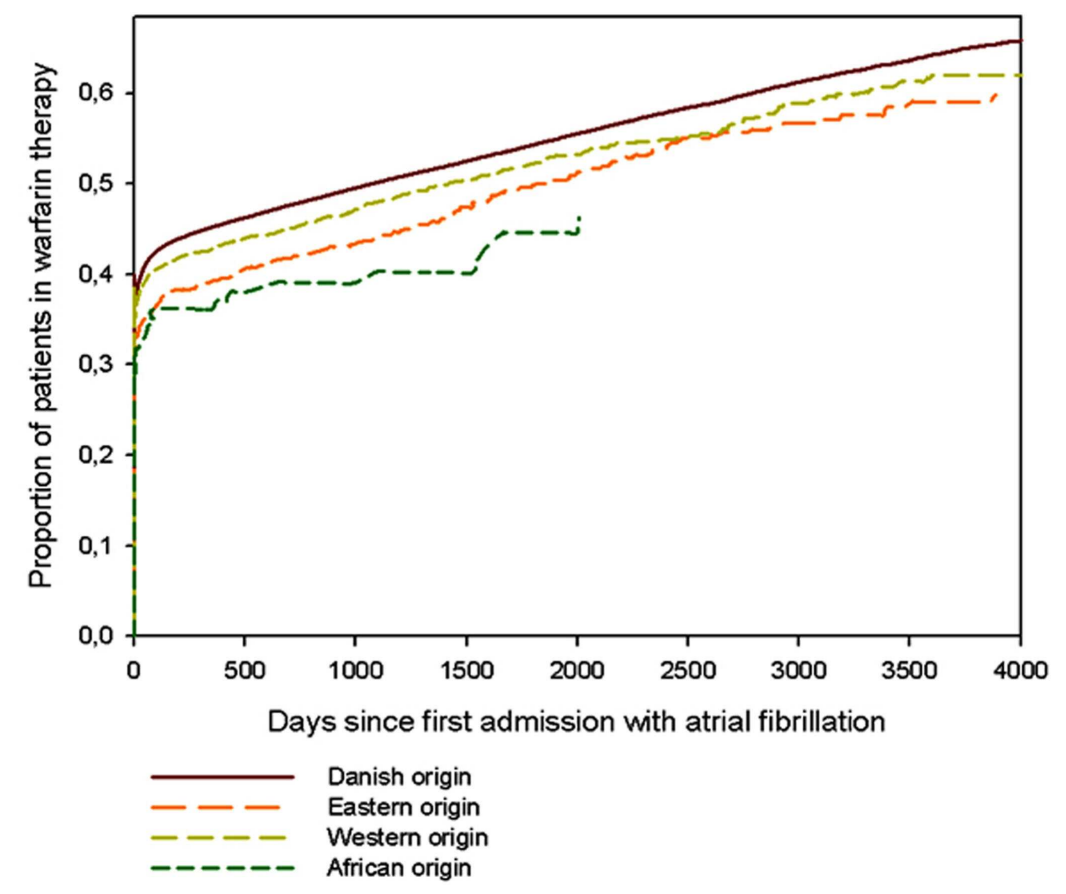

FIGURE 2 | Patients who were admitted with first-time atrial fibrillation, alive 7 days after discharge and have claimed a prescription of warfarin. Kaplan-Meier plots over time from first-admission with atrial fibrillation until first warfarin claim, stratified by ethnic origin. Curves end when all patients have been censored.

Table 3 | Multivariable Cox logistic regression analysis: time to first break of $\geq 90$ Days in warfarin treatment according to ethnicity.

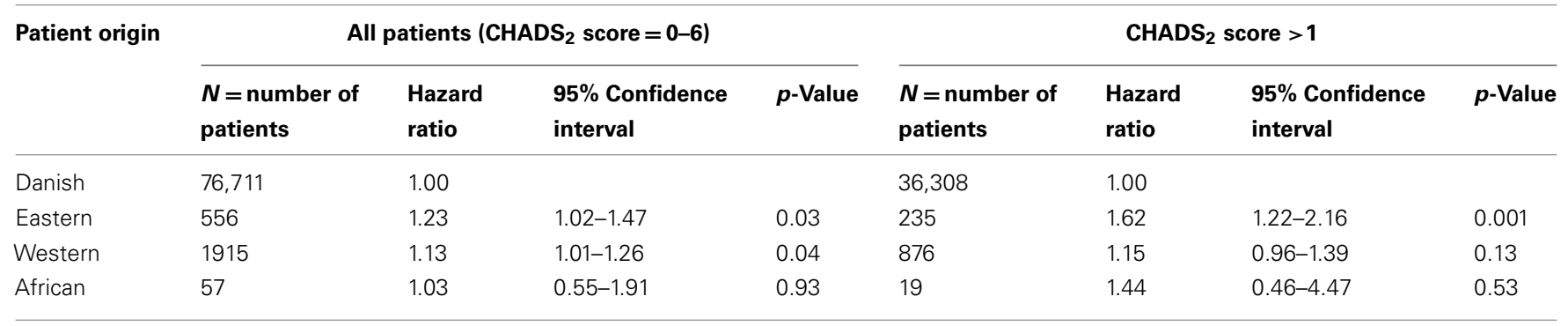

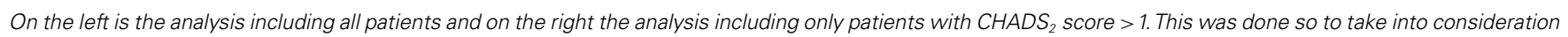

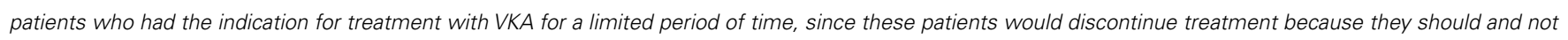
because of poor compliance. All models were adjusted for gender, age, ethnicity, and $\mathrm{CHADS}_{2}$ score.

also paramount and should be taken into account when analyzing doctor-patient communication (Stavropoulou, 2011).

Due to warfarin's narrow therapeutic range, numerous interactions and bleeding risk, warfarin therapy requires numerous control visits, blood tests, and continuous adjustment of dosage. Thus, it certainly demands clear understanding between doctor and patient. As mentioned above, doctor-patient relationship relies on a number of different aspects, all of which influence compliance to medical therapy. Divergent cultural/ethnic backgrounds between doctor and patient might introduce several aspects, such as language skills and perceptual bias that could lead to a problematic doctor-patient relationship. This could, at least in part, explain why AF patients of African and Eastern origin were prone not to receive proper warfarin treatment, in spite of equal access to the health care system. In an increasingly globalized world with multicultural societies, it has become of paramount importance to understand multicultural doctor-patient relationships and the mechanisms of importance to initiation of and persistence with treatment. Further research is needed to explore and address the causes of (non)initiation of and persistence with treatment. This will be particularly interesting in light of the new generation of anticoagulants, since these require less control, may be less demanding on doctor-patient relationship and thus improve adherence to treatment. 
Long-term persistence with warfarin in patients with atrial fibrillation stratified by ethnicity

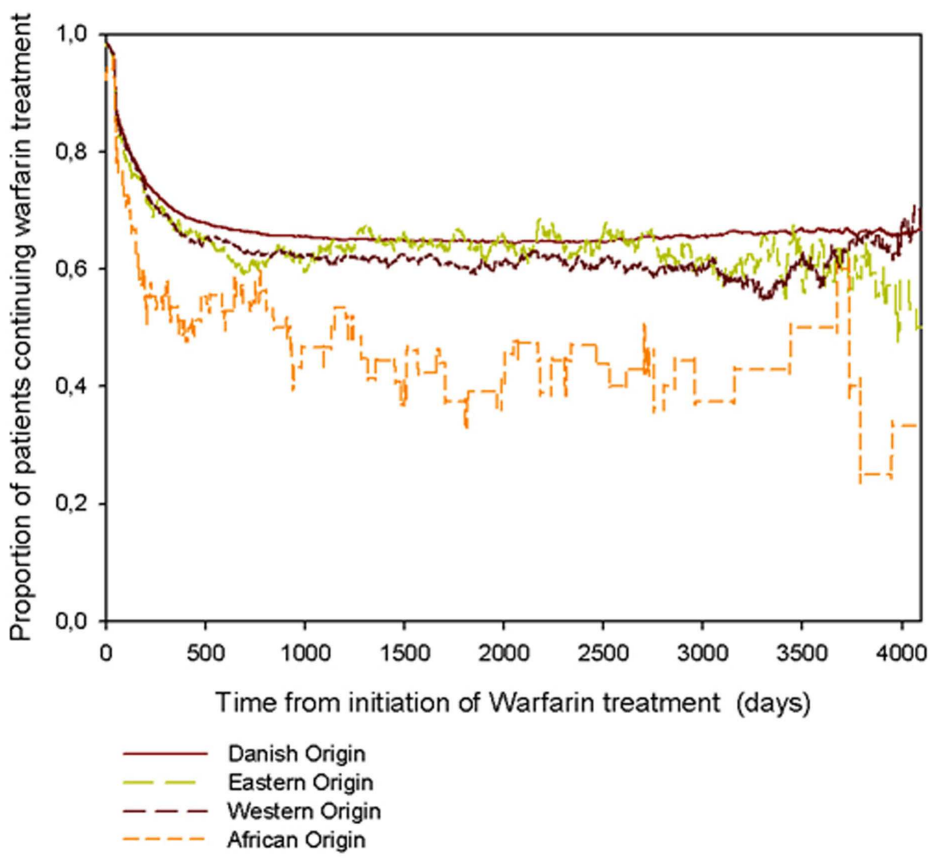

FIGURE 3 | Persistence with warfarin treatment stratified by ethnicity, in patients who were admitted with first-time atrial fibrillation in the period 1997-2009. Each point represents the number of patients with available medication divided by the number of patients alive at that time.
The lower incidence of AF among ethnic minorities could be due to the markedly younger age of these groups in the overall population, since AF increases with age (prevalence $<0.5 \%$ in age group 40-50 years; Camm et al., 2010). The majority of previous AF studies rely on Caucasian populations, yielding limited epidemiological data about AF incidence/prevalence and thromboembolic risk factors in non-Caucasian populations. However, our findings are in accordance with those of studies conducted in the primary care sector in England and among African Americans in the United States, that also have found lower AF prevalence/incidence among ethnic minorities and different thromboembolic risk profiles among ethnic groups (Lip et al., 1998; Gbadebo et al., 2011; Gill et al., 2011).

The main strength of our study is that it is a nationwide study that includes information about all hospital admissions in Denmark since 1978 and the first nationwide study of AF patients according to ethnicity. Furthermore, the diagnosis of AF, which was used as inclusion criteria, has a very high positive predictive value (99\%; Frost et al., 2007). Additionally, data on prescription claims have been proven accurate in other studies (Gaist et al., 1997). Finally, selection bias is unlikely to play a significant role, since all citizens in Denmark have free and equal access to a general practitioner and hospital care regardless of SES.

The main limitation of the study is its observational and retrospective nature which can lead to misclassification and inclusion bias. Our population includes only patients with hospital admittance which inevitably restricts the population of patients with AF. Risk factors and co-morbidity are probably underestimated, since diabetes, heart failure, and hypertension were diagnosed by prescription claims, thereby excluding patients who hold these diagnoses but are treated with lifestyle interventions alone or who do not purchase medications. The relative lower prevalence of co-morbidity and thereby lower $\mathrm{CHADS}_{2}$ score for patients of non-Danish origin could, in part, be due to a larger amount of nonDanish patients who are not receiving medications for diabetes, heart failure, and hypertension. It is also not possible to establish contraindications for treatment with warfarin in our study, which leads to include patients who interrupt warfarin treatment because of relevant contraindications in our analyses, as patients with poor persistence to warfarin treatment.

Our main goal was to address patient adherence to warfarin therapy according to ethnicity, among patients with AF. Our study found ethnic minorities undertreated, which also has been found in other disease populations (Schouten and Meeuwesen, 2006; Dominguez et al., 2010; Hempler et al., 2010; Kagawa-Singer et al., 2010). However, since there is no consensus as to how to address ethnicity, it is done so in various ways in the literature, using race, country of birth, or cultural background as ethnicity proxies (Bhopal and Donaldson, 1998; Mays et al., 2003; Stronks et al., 2009; Kagawa-Singer et al., 2010). In American studies, ethnicity is often defined as "self-defined" race, which can also be interpreted as an individual's cultural identity (Mays et al., 2003; Schauer et al., 2007; Kagawa-Singer et al., 2010). In certain European countries where immigration is recent and most immigrants were born in their country of "ethnic/cultural" origin, country of birth is usually used as ethnicity/cultural proxy (Stronks et al., 2009; Hempler et al., 2010; Jenum et al., 2012). Our approach was to create a more refined ethnicity proxy, in attempt to take cultural legacy into 
account. The limitation of all methods mentioned above, is that they do not take into account that ethnicity is one of many components of culture and therefore insufficient to fully understand all cultural aspects involved in behavior- in this case adherence to therapy (Schouten and Meeuwesen, 2006). However, it is beyond the scope of this register-based, epidemiological study to embrace other cultural parameters.

\section{CONCLUSION}

This study is the first nationwide study which has investigated the initiation of and persistence to warfarin treatment according to ethnicity in patients with first-time AF hospitalization. We found that patients of Eastern and African origin with increased thromboembolic risk did not initiate adequate warfarin treatment. Furthermore, when initiated, these patients were less likely to continue treatment. Thus, this study found patients of African and Eastern origin at increased risk of thromboembolic events compared to patients of Danish and Western origin, despite equal access to health care and medication. The hypothesis that ethnic minorities are undertreated, generated by smaller studies in other disease populations, is now supported by this nationwide study performed by linking national registries on an individual basis. Due to the retrospective and observational study design it was not possible to establish direct causality, leaving future research necessary in order to elucidate the underlying mechanisms that explain differences in adherence to warfarin treatment among

\section{REFERENCES}

Balarajan, R. (1991). Ethnic differences in mortality from ischaemic heart disease and cerebrovascular disease in England and Wales. BMJ 302, 560-564.

Bates, T. R., Connaughton, V. M., and Watts, G. F. (2009). Non-adherence to statin therapy: a major challenge for preventive cardiology. Expert Opin. Pharmacother. 10, 2973-2985.

Benner, J. S., Glynn, R. J., Mogun, H., Neumann, P. J., Weinstein, M. C., and Avorn, J. (2002). Long-term persistence in use of statin therapy in elderly patients. JAMA 288, 455-461.

Bhopal, R., and Donaldson, L. (1998). White, European, Western, Caucasian, or what? Inappropriate labeling in research on race, ethnicity, and health. Am. J. Public Health 88, 1303-1307.

Camm, A. J., Kirchhof, P., Lip, G. Y., Schotten, U., Savelieva, I., Ernst, S., Van Gelder, I. C., Al-Attar, N., Hindricks, G., Prendergast, B., Heidbuchel, H., Alfieri, O., Angelini, A., Atar, D., Colonna, P., De Caterina, R., De Sutter, J., Goette, A., Gorenek, B., Heldal, M., Hohloser, S. H., Kolh, P., Le Heuzey, J. Y., Ponikowski, P., Rutten, F. H., Vahanian, A., Auricchio, A., Bax, J., Ceconi, C., Dean, V., Filippatos, G., FunckBrentano, C., Hobbs, R., Kearney,

ethnic groups. This is of paramount importance in an increasingly globalized world. Furthermore, it is important that future studies address, beyond ethnicity, all possible driving factors of (non)initiation and persistence with treatment in general. This will be particularly interesting in light of the new generation of anticoagulants, which might render a very different adherence to treatment.

Our results also showed markedly different thromboembolic risk profiles and lower $\mathrm{CHADS}_{2}$ scores for patients of Eastern and African origin, which could be due to the younger age of these two subgroups. Since most previous AF studies rely on Caucasian populations further research is needed to explore these differences.

\section{AUTHOR CONTRIBUTIONS}

C. Torp-Pedersen, H. Dominguez, and C. M. Hansen made the primary contribution to the study conception and design. J. B. Olesen, H. Dominguez, and M. L. Hansen contributed to data collection and, C. Torp-Pedersen and C. M. Hansen made the primary contributions to data collection and analysis. C. M. Hansen had full access to all of the data in the study and takes responsibility for the integrity of the data and the accuracy of the data analysis. C. M. Hansen made the primary contribution to interpretation of results and writing of the manuscript. All authors contributed to interpretation of results, revising the manuscript critically for important intellectual content, and all approved the final manuscript.

Denmark. Front. Pharmacol. 1:142. doi:10.3389/fphar.2010.00142

Ekholm, O., Hesse, U., Davidsen, M., and Kjoller, M. (2009). The study design and characteristics of the Danish national health interview surveys. Scand. J. Public Health 37, 758-765.

Frost, L., Andersen, L. V., Vestergaard, P., Husted, S., and Mortensen, L. S. (2007). Trend in mortality after stroke with atrial fibrillation. Am. J. Med. 120, 47-53.

Gage, B. F., Waterman, A. D., Shannon, W., Boechler, M., Rich, M. W., and Radford, M. J. (2001). Validation of clinical classification schemes for predicting stroke: results from the National Registry of Atrial Fibrillation. JAMA 285, 2864-2870.

Gaist, D., Sorensen, H. T., and Hallas, J. (1997). The Danish prescription registries. Dan. Med. Bull. 44, 445-448.

Gbadebo, T. D., Okafor, H., and Darbar, D. (2011). Differential impact of race and risk factors on incidence of atrial fibrillation. Am. Heart J. 162, 31-37.

Gill, P. S., Calvert, M., Davis, R., Davies, M. K., Freemantle, N., and Lip, G. Y. (2011). Prevalence of heart failure and atrial fibrillation in minority ethnic subjects: the Ethnic-Echocardiographic Heart of England Screening Study (EECHOES). PLoS ONE 6, e26710. doi:10.1371/journal.pone.0026710

Gislason, G. H., Rasmussen, J. N., Abildstrom, S. Z., Gadsboll, N., Buch, P., Friberg, J., Rasmussen, S., Kober, L., Stender, S., Madsen, M., and Torp-Pedersen, C. (2006). Long-term compliance with betablockers, angiotensin-converting enzyme inhibitors, and statins after acute myocardial infarction. Eur. Heart J. 27, 1153-1158.

Harding, S., Rosato, M., and Teyhan, A. (2008). Trends for coronary heart disease and stroke mortality among migrants in England and Wales, 1979-2003: slow declines notable for some groups. Heart 94, 463-470.

Hempler, N. F., Diderichsen, F., Larsen, F. B., Ladelund, S., and Jorgensen, T. (2010). Do immigrants from Turkey, Pakistan and Yugoslavia receive adequate medical treatment with beta-blockers and statins after acute myocardial infarction compared with Danish-born residents? A register-based follow-up study. Eur. J. Clin. Pharmacol. 66, 735-742.

Hertz, R. P., McDonald, M., Unger, A. N., and Lustik, M. B. (2007). Racial and ethnic disparities in the prevalence and management of cardiovascular risk factors in the United States workforce. J. Occup. Environ. Med. 49, 1165-1175. 
Hozawa, A., Folsom, A. R., Sharrett, A. R., and Chambless, L. E. (2007). Absolute and attributable risks of cardiovascular disease incidence in relation to optimal and borderline risk factors: comparison of African American with white subjects-Atherosclerosis Risk in Communities Study. Arch. Intern. Med. 167, 573-579.

Hughes, M., and Lip, G. Y. (2008). Stroke and thromboembolism in atrial fibrillation: a systematic review of stroke risk factors, risk stratification schema and cost effectiveness data. Thromb. Haemost. 99, 295-304.

Jenum, A. K., Morkrid, K., Sletner, L., Vange, S., Torper, J. L., Nakstad, B., Voldner, N., Rognerud-Jensen, O. H., Berntsen, S., Mosdol, A., Skrivarhaug, T., Vardal, M. H., Holme, I., Yajnik, C. S., and Birkeland, K. I. (2012). Impact of ethnicity on gestational diabetes identified with the WHO and the modified International Association of Diabetes and Pregnancy Study Groups criteria: a population-based cohort study. Eur. J. Endocrinol. 166, 317-324.

Joensen, A. M., Jensen, M. K., Overvad, K., Dethlefsen, C., Schmidt, E., Rasmussen, L., Tjonneland, A., and Johnsen, S. (2009). Predictive values of acute coronary syndrome discharge diagnoses differed in the Danish National Patient Registry. J. Clin. Epidemiol. 62, 188-194.

Kagawa-Singer, M., Dadia, A. V., Yu, M. C., and Surbone, A. (2010). Cancer, culture, and health disparities: time to chart a new course? CA Cancer J. Clin. 60, 12-39.

Kaplan, R. C., Bhalodkar, N. C., Brown, E. J. Jr., White, J., and Brown, D. L. (2004). Race, ethnicity, and sociocultural characteristics predict noncompliance with lipidlowering medications. Prev. Med. 39, 1249-1255.

Krarup, L. H., Boysen, G., Janjua, H., Prescott, E., and Truelsen, T. (2007). Validity of stroke diagnoses in a National Register of Patients. Neuroepidemiology 28, 150-154.

Kumler, T., Gislason, G. H., Kirk, V., Bay, M., Nielsen, O. W., Kober, L., and Torp-Pedersen, C. (2008). Accuracy of a heart failure diagnosis in administrative registers. Eur. J. Heart Fail. 10, 658-660.

Lip, G. Y., Bawden, L., Hodson, R., Rutland, E., Snatchfold, J., and Beevers, D. G. (1998). Atrial fibrillation amongst the Indo-Asian general practice population. The West Birmingham Atrial Fibrillation Project. Int. J. Cardiol. 65, 187-192.

Lip, G. Y., Nieuwlaat, R., Pisters, R., Lane, D. A., and Crijns, H. J. (2010). Refining clinical risk stratification for predicting stroke, and thromboembolism in atrial fibrillation using a novel risk factor-based approach: the euro heart survey on atrial fibrillation. Chest 137, 263-272.

Madsen, M., Davidsen, M., Rasmussen, S., Abildstrom, S. Z., and Osler, M. (2003). The validity of the diagnosis of acute myocardial infarction in routine statistics: a comparison of mortality and hospital discharge data with the Danish MONICA registry. J. Clin. Epidemiol. 56, 124-130.

Mayberry, R. M., Mili, F., and Ofili, E. (2000). Racial and ethnic differences in access to medical care. Med. Care Res. Rev. 57(Suppl. 1), 108-145.

Mays, V. M., Ponce, N. A., Washington, D. L., and Cochran, S. D. (2003). Classification of race and ethnicity: implications for public health. Annu. Rev. Public Health 24, 83-110.
McWilliams, J. M., Meara, E., Zaslavsky, A. M., and Ayanian, J. Z. (2009). Differences in control of cardiovascular disease and diabetes by race, ethnicity, and education: U.S. trends from 1999 to 2006 and effects of medicare coverage. Ann. Intern. Med. 150, 505-515.

Ogilvie, I. M., Newton, N., Welner, S. A., Cowell, W., and Lip, G. Y. (2010). Underuse of oral anticoagulants in atrial fibrillation: a systematic review. Am. J. Med. 123 638-645.e634.

Olesen, J. B., Lip, G. Y., Hansen, M. L., Hansen, P. R., Tolstrup, J. S., Lindhardsen, J., Selmer, C., Ahlehoff, O., Olsen, A. M., Gislason, G. H., and Torp-Pedersen, C. (2011). Validation of risk stratification schemes for predicting stroke and thromboembolism in patients with atrial fibrillation: nationwide cohort study. $B M$ ) 342, d124.

Schauer, D. P., Johnston, J. A., Moomaw, C. J., Wess, M., and Eckman, M. H. (2007). Racial disparities in the filling of warfarin prescriptions for nonvalvular atrial fibrillation. Am. J. Med. Sci. 333 67-73.

Schouten, B. C., and Meeuwesen, L. (2006). Cultural differences in medical communication: a review of the literature. Patient Educ. Couns. 64 21-34.

Severinsen, M. T., Kristensen, S. R. Overvad, K., Dethlefsen, C., Tjonneland, A., and Johnsen, S. P. (2010). Venous thromboembolism discharge diagnoses in the Danish National Patient Registry should be used with caution. J. Clin. Epidemiol. 63, 223-228.

Stavropoulou, C. (2011). Nonadherence to medication and doctor-patient relationship: Evidence from a European survey. Patient Educ. Couns. 83, 7-13.

Stronks, K., Kulu-Glasgow, I., and Agyemang, C. (2009). The utility of 'country of birth' for the classification of ethnic groups in health research: the Dutch experience. Ethn. Health 14, 255-269.

Trivedi, A. N., Zaslavsky, A. M., Schneider, E. C., and Ayanian, J. Z (2006). Relationship between quality of care and racial disparities in Medicare health plans. JAMA 296, 1998-2004.

Conflict of Interest Statement: The authors declare that the research was conducted in the absence of any commercial or financial relationships that could be construed as a potential conflict of interest.

Received: 25 October 2011; accepted: 07 June 2012; published online: 28 June 2012.

Citation: Hansen CM, Olesen JB, Hansen ML, Azimi A, Torp-Pedersen $C$ and Dominguez $H$ (2012) Initiation and persistence with warfarin therapy in atrial fibrillation according to ethnicity. Front. Pharmacol. 3:123. doi: 10.3389/fphar.2012.00123

This article was submitted to Frontiers in Pharmaceutical Medicine and Outcomes Research, a specialty of Frontiers in Pharmacology. Copyright (c) 2012 Hansen, Olesen, Hansen, Azimi, Torp-Pedersen and Dominguez. This is an open-access article distributed under the terms of the Creative Commons Attribution Non Commercial License, which permits noncommercial use, distribution, and reproduction in other forums, provided the original authors and source are credited. 